\title{
Interactive effects of multiple climate change variables on trophic interactions: a meta-analysis
}

\author{
Adam E Rosenblatt ${ }^{1 *}$ and Oswald J Schmitz ${ }^{2}$
}

\begin{abstract}
Background: Climate change is expected to simultaneously alter many of the abiotic qualities of ecosystems as well as biotic interactions, especially trophic interactions. However, research to date has mostly focused on elucidating the effects of single climate change variables on individual species. Here, we use established meta-analysis techniques to synthesize the existing literature on the interactive effects of multiple climate change variables on trophic interactions.
\end{abstract}

Results: Most of the studies included in our meta-analysis examined plant-insect herbivore interactions. We found that the majority of trophic interaction response variables (55\%) displayed multiplicative reactions to interacting climate change variables while 36\% and 9\% displayed antagonistic and synergistic reactions, respectively. We also found that only one of six climate change variable pairings had consistent positive or negative effects on trophic relationships, largely because interaction type and magnitude were both highly context dependent across the pairings. Most notably, males and females frequently responded differently to interacting climate change variables, and the response strength frequently varied with the underlying nutrient load of the system.

Conclusions: Our results suggest that trophic interactions commonly respond antagonistically to interacting climate change variables whereas synergistic and simple additive/multiplicative reactions are less common than previously thought. In addition, response type and magnitude are highly context dependent. These findings further suggest that in many cases, future ecosystem responses to climate change, whether positive or negative, may be dampened relative to predictions based on experiments that investigate the effects of single climate change variables on single species. However, there is a paucity of work that has focused on the effects of interacting climate change variables on dynamic biotic relationships, likely because such research requires complex experimentation. Increasing the complexity of climate change research is necessary for accurately predicting ecosystem responses.

Keywords: Carbon dioxide, Feeding, Food web, Global change, Log response ratio, Ozone, Photoperiod, Rainfall, Temperature, Ultraviolet radiation

\section{Background}

Climate change stands to alter ecosystem structure and function through numerous and diverse pathways. In addition to changing the fundamental abiotic qualities of ecosystems (e.g., temperature, water availability, $\mathrm{CO}_{2}$ concentration), climate change is expected to alter the behavior and life history characteristics of organisms which could lead to dramatic changes in inter and intraspecific competition, predation, mutualisms, species distributions, biodiversity patterns, and the provisioning of

\footnotetext{
* Correspondence: adam.rosenblatt@yale.edu

${ }^{1}$ Yale University, Yale Climate and Energy Institute, New Haven, CT, USA

Full list of author information is available at the end of the article
}

ecosystem services [1-6]. Yet most studies have tended to examine climate effects on biotic components by focusing on single species while treating the larger community as background variation [7] and by typically focusing on a single climate change variable at a time [8-10]. Whether or not such approaches adequately capture how systems will respond to climate change remains uncertain.

We address this uncertainty by comparing the responses of interacting species subjected to the manipulation of a single climate change variable with their responses to simultaneous manipulations of multiple climate change variables. Specifically, we use a meta-analytic approach to 
synthesize existing literature, identify trends and patterns, and highlight areas that deserve immediate attention and other areas in which consensus may have already been reached [11]. Meta-analysis, as used in ecological research, is a statistical technique that combines data from independent studies to elucidate overall, net effect magnitudes of biotic or abiotic variables on a response of interest $[12,13]$. Meta-analysis has already been effective in providing synthetic insights into the interacting effects of multiple anthropogenic variables, or "stressors", like pollutants, invasive species, habitat fragmentation, and eutrophication on responses like species interactions within communities and ensuing ecosystem functioning [2,8,9,14-19]. But the effects of interacting climate change variables on these responses have yet to be the subject of synthesis. Meta-analysis is particularly suited for synthesizing results of climate change studies that cover many different species and habitat types because such studies frequently vary in sample size and statistical power, issues that are explicitly accounted for in meta-analysis. Furthermore, meta-analysis is useful in research on climate change as individual studies often produce conflicting results [13].

Our focus here is on the role of simultaneously (and rapidly) changing climate variables on trophic interactions, as these factors are among the major drivers of ecosystem structure and function [20]. Using established meta-analysis techniques, we determined the frequency of different interaction types (multiplicative, synergistic, antagonistic: see the "Effect size calculations" section) across different combinations of climate change variables and then elucidated the potential mechanisms underlying the interactions. We also investigated how the environmental context in which the variables were manipulated influenced the nature and strength of trophic interactions (i.e., examined context dependency) because many studies manipulated additional factors (e.g., nutrient levels, community composition) in addition to systematic manipulation of the common climate variables that are the focus of our analysis.

Our analysis was motivated by the broad, working hypothesis that non-linear (synergistic or antagonistic) interactions would largely result from combinations of climate change variables that operated through different pathways $[10,14]$. For example, in a plant-herbivorous insect trophic interaction, warmer temperatures may increase the insect's metabolism and an increase in atmospheric $\mathrm{CO}_{2}$ may decrease the nutritional quality of the plant [21-23]. Thus, any simultaneous increases in levels of these two climate change variables stand to reinforce each other to increase the feeding rate of the insect, but through different pathways, and thereby result in a net synergistic trophic interaction.

\section{Results}

\section{Database}

Our literature search produced 2,122 candidate studies, of which $15.5 \%$ ( $n=328)$ were experimental or modeling studies that examined the effects of at least one climate change variable on multi-trophic interactions. Only $2.2 \%$ $(n=47)$ of the studies examined the effects of multiple interacting climate change variables, with $1.9 \%(n=41)$ using two interacting climate change variables and $0.3 \%$ $(n=6)$ using three interacting climate change variables. Of these 47 studies, 6 did not report all the necessary mean and variance data from the 4 required treatment groups and 7 did not report data for any response variables directly related to feeding interactions. Therefore, 34 of the studies from the original candidate pool met all of our criteria and were included in our analyses. In the terrestrial studies $(n=26)$, most of the feeding interactions examined were either between plants and herbivorous insects, or plants, herbivorous insects, and parasitoids, but two studies examined plant-microbial decomposer interactions. In the marine studies $(n=5)$, all the feeding interactions examined involved plants and herbivorous invertebrates. In the freshwater studies $(n=3)$, all of the feeding interactions examined were between phytoplankton and zooplankton. Additional details about each study, including study length and climate change variables manipulated, are provided in Table 1.

Collectively, the 34 studies reported 126 response variables related to feeding interactions, but 11 were excluded because they were redundant (see the "Methods" section). Of the remaining 115 response variables, 65\% $(n=75)$ measured weights of individuals or the biomass of groups, $34 \%(n=39)$ measured feeding rates or growth rates, and $1 \%(n=1)$ measured the size of individuals. Across the 115 response variables, 6 unique combinations of climate change variables were tested: $\mathrm{CO}_{2} \times$ temperature $(n=38), \mathrm{CO}_{2} \times \mathrm{O}_{3}(n=33)$, temperature $\times$ rainfall $(n=18)$, temperature $\times$ photoperiod $(n=14), \mathrm{CO}_{2} \times$ rainfall $(n=9)$, and temperature $\times$ ultraviolet radiation (UV; $n=3$ ).

\section{Effect sizes and interaction types}

Only one of the summary effect sizes for the climate change variables tested in isolation (UV) and one of the climate variable interaction pairings (temperature $\times \mathrm{UV}$ ) were significantly positive or negative (Figure 1). The majority of response variables $(55 \% ; n=63)$ displayed multiplicative reactions (the null hypothesis) to interacting climate change variables while $36 \%(n=41)$ and $9 \%$ $(n=11)$ displayed antagonistic and synergistic reactions, respectively. For each of the six unique combinations of climate change variables, the proportions of multiplicative, synergistic, and antagonistic interactions varied 
Table 1 Studies used in meta-analysis

\begin{tabular}{|c|c|c|c|c|c|c|c|c|c|}
\hline \multirow[t]{2}{*}{ Source } & \multirow{2}{*}{$\begin{array}{c}\text { Habitat } \\
\text { type }\end{array}$} & \multirow{2}{*}{$\begin{array}{l}\text { Length of } \\
\text { study (days) }\end{array}$} & \multirow{2}{*}{$\begin{array}{l}\text { Number of } \\
\text { trophic levels }\end{array}$} & \multicolumn{6}{|c|}{ Climate variables manipulated } \\
\hline & & & & Temp & $\mathrm{CO}_{2}$ & Rain & $\mathrm{O}_{3}$ & Photo & UV \\
\hline [24] & Freshwater & 50 & Food web & $x$ & & $x$ & & & \\
\hline [25] & Freshwater & 4 & Food web & $x$ & & & & & $x$ \\
\hline [26] & Freshwater & 50 & 2 & $x$ & & & & & $x$ \\
\hline [27] & Marine & 36 & Food web & $x$ & $x$ & & & & \\
\hline [28] & Marine & 35 & 2 & $x$ & $x$ & & & & \\
\hline [29] & Marine & 11 & 2 & $x$ & $x$ & & & & \\
\hline [30] & Marine & 14 & 2 & $x$ & $x$ & & & & \\
\hline [31] & Marine & 42 & 2 & $x$ & & $x$ & & & \\
\hline [32] & Terrestrial & 1461 & 3 & $x$ & $x$ & & & & \\
\hline [33] & Terrestrial & 120 & 3 & $x$ & $x$ & & & & \\
\hline [34] & Terrestrial & 70 & 2 & $x$ & $x$ & & & & \\
\hline [35] & Terrestrial & 42 & 2 & $x$ & $x$ & & & & \\
\hline [36] & Terrestrial & 56 & 2 & $x$ & $x$ & & & & \\
\hline [37] & Terrestrial & 63 & 2 & $x$ & $x$ & & & & \\
\hline [38] & Terrestrial & 100 & 2 & $x$ & $x$ & & & & \\
\hline [39] & Terrestrial & 100 & 2 & $x$ & $x$ & & & & \\
\hline [40] & Terrestrial & 6 & 2 & $x$ & $x$ & & & & \\
\hline [41] & Terrestrial & 15 & Food web & $x$ & $x$ & $x$ & & & \\
\hline [42] & Terrestrial & 692 & Food web & $x$ & $x$ & $x$ & & & \\
\hline [43] & Terrestrial & 35 & 2 & $x$ & $x$ & $x$ & & & \\
\hline [44] & Terrestrial & 1460 & Food web & & $x$ & $x$ & & & \\
\hline [45] & Terrestrial & Unknown & 2 & & $x$ & $x$ & & & \\
\hline [46] & Terrestrial & 46 & 2 & & $x$ & $x$ & & & \\
\hline [47] & Terrestrial & 60 & 3 & & $x$ & & $x$ & & \\
\hline [48] & Terrestrial & 78 & 3 & & $x$ & & $x$ & & \\
\hline [49] & Terrestrial & 62 & 2 & & $x$ & & $x$ & & \\
\hline [50] & Terrestrial & 45 & 2 & & $x$ & & $x$ & & \\
\hline [51] & Terrestrial & 55 & 2 & & $x$ & & $x$ & & \\
\hline [52] & Terrestrial & 45 & 2 & & $x$ & & $x$ & & \\
\hline [53] & Terrestrial & 21 & 2 & & $x$ & & $x$ & & \\
\hline [54] & Terrestrial & 7 & 2 & & $x$ & & $x$ & & \\
\hline [55] & Terrestrial & 1096 & 2 & & $x$ & & $x$ & & \\
\hline [56] & Terrestrial & 45 & 2 & & $x$ & & $x$ & & \\
\hline [57] & Terrestrial & 1 & 3 & $x$ & & & & $x$ & \\
\hline
\end{tabular}

"Food web" indicates that multiple species at each of two or more trophic levels were studied. " $\mathrm{X}$ " indicates that a climate variable was manipulated in the particular study. All studies are experimental except [33] which is a modeling study.

"Temp"= temperature, "Photo"= photoperiod, and "UV"= ultraviolet radiation.

widely (Figure 2). For example, for both the $\mathrm{CO}_{2} \times$ temperature and rain $\times$ temperature pairings, roughly $35 \%$ of the response variables showed antagonistic interactions, $60 \%$ showed multiplicative interactions, and $5 \%$ showed synergistic interactions. In contrast, for the $\mathrm{CO}_{2} \times \mathrm{O}_{3}$ pairing, $85 \%$ of the response variables were evenly divided between antagonistic and multiplicative interactions while synergistic interactions accounted for the remaining 15\% (Figure 2).

\section{Context dependence}

We found that between $6 \%$ and $50 \%$ of interaction types changed across different contexts, with the lowest percentage of interaction type variation caused by community composition and the highest percentage of interaction type variation caused by sex (Table 2). Furthermore, we found that between $5 \%$ and $83 \%$ of interaction effect size magnitudes were significantly different across contexts, 

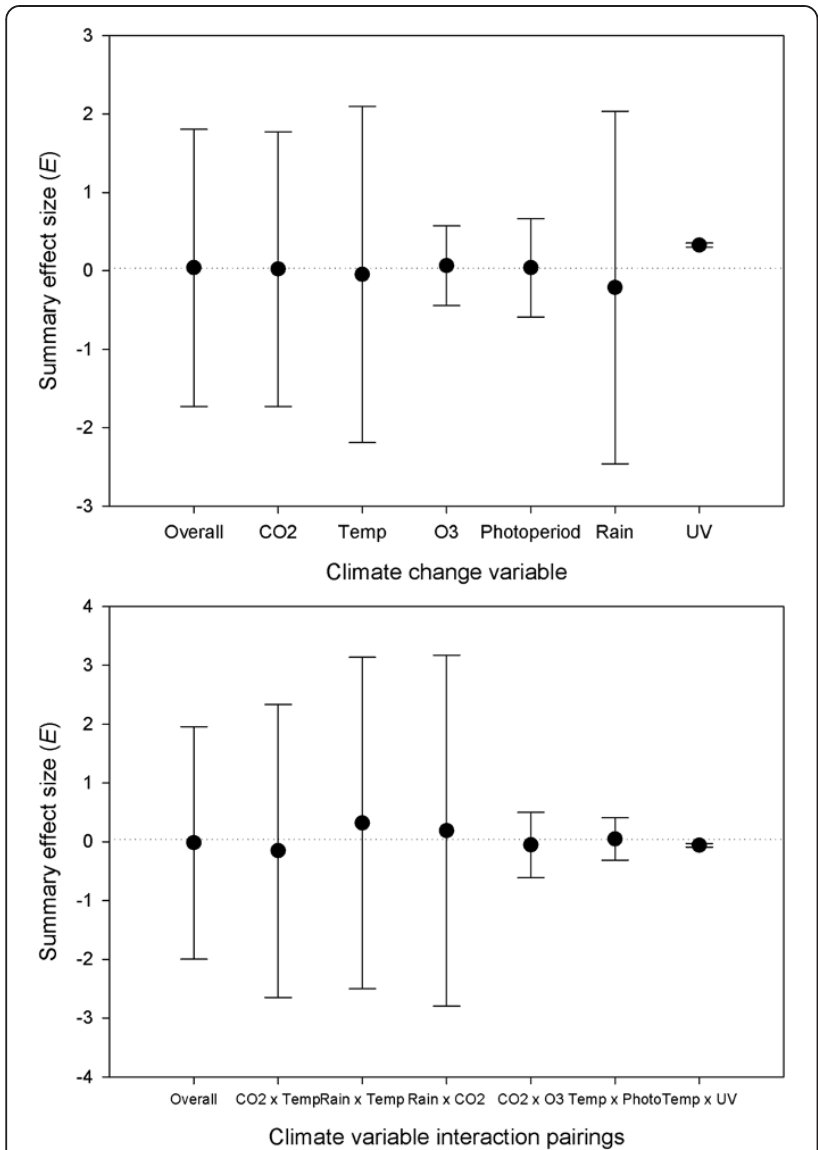

Figure 1 Summary effect sizes of individual climate change variables (top) and climate variable interaction pairings (bottom) on trophic relationships. Circles represent mean summary effect sizes, and lines represent 95\% confidence intervals (Cl). If $95 \%$ Cls overlap zero (dotted line), then the summary effect size is not significantly positive or negative. "Temp"= temperature, "Photo"= photoperiod, and "UV"= ultraviolet radiation.

with the lowest percentage of significant differences caused by species identity and the highest percentage of significant differences caused by nutrient levels (Table 2).

\section{Publication bias}

The possibility of publication bias in the literature we surveyed likely had no effect on our results. First, we found no significant correlation between effect size and study variance ( $\tau=0.099, Z=1.57, p=0.12$ ). Second, Rosenthal's fail-safe number (1607.5) far exceeds the threshold value (585) produced by the equation $5 n+10$.

\section{Discussion}

This study reviewed the climate change literature to begin to offer synthetic understanding of the possible effects of multiple interacting climate change variables on trophic interactions. It is clear from the relatively small number of studies available $(n=47)$ and the even smaller number of studies that fit all of our meta-

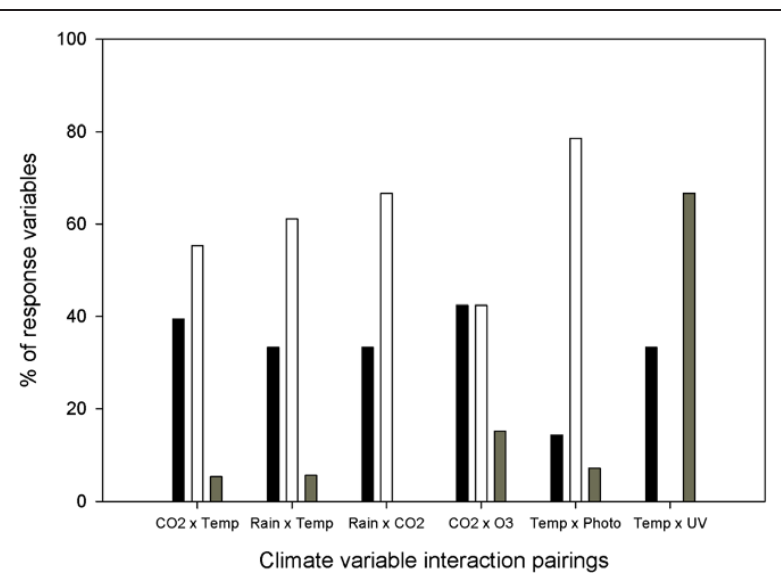

Figure 2 Percentage of different response variables across climate variable interaction pairings that fell into three interaction categories. Black bars= antagonistic, white bars= multiplicative, grey bars= synergistic. "Temp" = temperature, "Photo"= photoperiod, and "UV"= ultraviolet radiation.

analytical criteria $(n=34)$ that further experimental research is needed on this topic. Despite the small number of studies, our analysis revealed a broad range of reactions to interacting climate change variables by trophic response variables that have thus far been widely overlooked.

Our analysis suggests that trophic relationships between organisms may frequently respond antagonistically to interacting climate change variables relative to single factor manipulations, whereas synergistic responses are rare. This result runs counter to assertions made in a modeling study that examined potential effects of interacting global change drivers on biodiversity patterns and hypothesized that the global change drivers would generally interact synergistically or not at all [15]. However, more recent meta-analytic studies that address the effects of multiple global change variables on species performances broadly agree with our results. For example, total aboveground plant biomass frequently responds antagonistically to $\mathrm{CO}_{2} \times$ temperature treatments relative to single factor manipulations [18], while animal mortality does not generally respond synergistically to interacting stressors [17]. A third study suggested that antagonisms and synergisms between global change drivers occur at roughly equal rates [9]. Importantly, all of these meta-analyses, including our own, examined different types of response variables yet came to roughly similar conclusions: antagonistic reactions to interacting global change drivers by organisms appear to be quite common while synergistic and simple additive/multiplicative reactions are less common than previously thought.

Another important conclusion of our meta-analysis is that reactions of trophic response variables to interacting climate change variables can be highly context dependent. 
Table 2 Context dependence of trophic response variables examined across all 34 studies that manipulated multiple climate change variables

\begin{tabular}{|c|c|c|c|c|c|}
\hline Context & $\begin{array}{c}\text { Number of } \\
\text { interaction } \\
\text { pairs }\end{array}$ & $\begin{array}{c}\text { Numbers that } \\
\text { changed interaction } \\
\text { type }\end{array}$ & $\begin{array}{l}\% \text { that changed } \\
\text { interaction type }\end{array}$ & $\begin{array}{c}\text { Numbers that changed } \\
\text { interaction effect size } \\
\text { magnitude }\end{array}$ & $\begin{array}{l}\% \text { that changed interaction } \\
\text { effect size magnitude }\end{array}$ \\
\hline Sex & 14 & 7 & 50 & 5 & 36 \\
\hline Nutrient level & 6 & 2 & 33 & 5 & 83 \\
\hline Genotype & 15 & 5 & 33 & 8 & 53 \\
\hline Species identity & 20 & 6 & 30 & 1 & 5 \\
\hline $\begin{array}{l}\text { Climate variable } \\
\text { combination }\end{array}$ & 12 & 2 & 17 & 3 & 25 \\
\hline $\begin{array}{l}\text { Community } \\
\text { composition }\end{array}$ & 17 & 1 & 6 & 3 & 18 \\
\hline
\end{tabular}

For example, the interaction type (multiplicative, synergistic, antagonistic) was different between males and females $50 \%$ of the time and the interaction effect size magnitude was different between varying nutrient levels $83 \%$ of the time. Thus, increasing the number of global change drivers examined in a factorial study may alter the interaction outcome and/or the interaction effect size magnitude [58], and demographic and community composition factors, if not properly controlled for, could have additional effects. It has even been suggested that higher order interactions of global change drivers produce smaller magnitude responses which, if generally true, would mean that anticipated positive and negative impacts of global change might be dampened relative to current predictions based on single factor studies [58].

Some of the climate change variable pairings frequently produced unexpected emergent interaction types, suggesting that each climate variable exerts effects on trophic relationships through multiple pathways. As an example, consider the effects of the $\mathrm{CO}_{2} \times$ temperature interaction on a typical plant-herbivorous insect feeding relationship, which was the most commonly examined trophic relationship across the studies we analyzed. Plant quality from the perspective of herbivorous insects is generally determined by the nutrient profile of the plant (particularly the C:N ratio for nitrogen limited insects $[59,60])$, any defensive chemical compounds produced by the plant (e.g., phenolics and terpenes), and the physical traits of plant tissues (e.g., leaf toughness and thickness [22]). In general, plants raised in environments with high concentrations of $\mathrm{CO}_{2}$ exhibit high $\mathrm{C}: \mathrm{N}$ ratios, increased production of phenolics, and increased leaf toughness and thickness [21,22]. These relatively low-quality plants force insects to increase their feeding rates to compensate for the decreased food quality [61]. Increases in atmospheric $\mathrm{CO}_{2}$ have few direct effects on insects [62], except in a few special cases such as hematophagous insects and phytophagous insect larvae that use $\mathrm{CO}_{2}$ gradients to locate feeding opportunities [63]. In contrast, increased temperatures do not generally affect plant $\mathrm{C}: \mathrm{N}$ ratios or physical traits but they can increase terpene production and can either cause increases or decreases in plant phenolics [22]. Insects exposed to increased temperatures generally exhibit increased metabolism and respiration [64], resulting in increased feeding, development, and reproduction rates [62].

On the basis of the individual effects of $\mathrm{CO}_{2}$ and temperature on plant quality and insect metabolism discussed above, we would logically expect the interactive effects of $\mathrm{CO}_{2}$ and temperature to promote synergistic and multiplicative responses in plant-herbivorous insect trophic interactions. However, our meta-analysis revealed more antagonistic reactions $(n=12)$ than synergistic and multiplicative reactions combined $(n=11)$. There are many potential explanations for this disparity. First, the inclusion of an additional trophic level, (i.e., a predator of the herbivorous insect) could alter the plant-herbivorous insect trophic relationship (e.g., [32]) by changing the timing and extent of feeding or the development rate of the herbivorous insect. Second, all the parts of a plant may not respond to climate change variables on the same time scales and mobile herbivorous insects could therefore seek out and continue to consume plant tissues with high nutrient value (e.g., [35]). Third, many plant and herbivorous insect species may physiologically respond differently to identical climate manipulations (e.g., $[40,65])$, and therefore, changes in trophic relationships may not be consistent across all scenarios. Lastly, if experiments testing the effects of interacting climate change variables on trophic relationships are not long enough, they may miss important interactions that only emerge over long time periods [40].

It is noteworthy that not all studies of the effects of climate change on ecological interactions may need to consider the interactive effects of all climate change variables. Though most climate change variables likely interact at least indirectly, the effects of some of these interactions on ecological relationships may be negligible. Indeed, one of the possible reasons for why we found so few studies that fit our meta-analysis criteria is that researchers may exclude some climate change variables from their experiments if they are fairly certain the variables will have little 
impact on their results. However, given the frequent discoveries of "ecological surprises" in ecological climate change research (e.g., [24]), we encourage researchers to continue to test for the potential unexpected interactions between climate change variables rather than dismiss candidate variables under the presumption that they will not have an effect.

Our results lead us to agree with other recent metaanalyses and reviews: to understand and predict the effects of climate change and other anthropogenic forms of global change on ecosystem structure, function, and services, the complexity of experimental and modeling studies must increase to more closely reflect natural conditions $[10,66]$. The experimental challenge will be to account for a diverse array of factors [7], including the two we have highlighted in our meta-analysis: the interactions between climate change variables and the direct and indirect interactions that permeate food webs $[1,2,67]$. Also, future studies should 1) run longer to better understand the evolutionary and demographic stability of altered trophic interactions over multiple generations $[23,68], 2)$ examine food webs in different kinds of ecosystems (the large majority to date have been terrestrial), 3) examine trophic relationships across more than simple two- and three-level linear interactions and beyond plantinsect feeding scenarios, 4) focus on more climate change variable pairings beyond $\mathrm{CO}_{2} \times$ temperature and $\mathrm{CO}_{2} \times$ $\mathrm{O}_{3}$ (by far the most studied variable pairings to date), and 5) examine the role of body size and movement capabilities in determining the response of trophic relationships to interacting climate change variables. These recommended amendments to current experimental practices will help to increase realism by accounting for the inherent complexity of natural trophic interactions and thereby bring us closer to more accurate predictions of the consequences of climate change on ecosystem structure and function.

\section{Conclusions}

Despite the relatively small amount of research that has examined the effects of interacting climate change variables on trophic interactions, our meta-analysis of this literature revealed some striking patterns. First, trophic interactions frequently respond multiplicatively and antagonistically to interacting climate change variables, while synergistic responses are relatively rare. Second, both response type and magnitude are highly context dependent, indicating that unanticipated emergent effects of climate change on ecosystems are likely to occur. There is a paucity of work that has focused on the effects of interacting climate change variables on dynamic biotic relationships, likely because such research requires complex experimentation and in-depth understanding of many species' physiology, behavior, and life history. Nevertheless, increasing the complexity of climate change research is necessary for accurately predicting ecosystem responses and informing future conservation and management strategies.

\section{Methods \\ Database development}

We used Web of Science to search the literature for factorial experimental or modeling studies that investigated the individual and interactive effects of at least two climate change variables on the feeding interactions between species at different trophic levels. We chose to focus on six climate change variables that are most frequently included in experiments: temperature, precipitation, $\mathrm{CO}_{2}, \mathrm{O}_{3}$, photoperiod, and ultraviolet radiation. We used the search terms "food web", predator" or predation, prey or herbivore", herbivore* and plant*, parasite* and host" in combination with "climate change", "climatic change", "global warming", "global change", and "global environmental change". We supplemented our database by searching through the literature-cited sections of key review papers and meta-analyses as well as publications from research sites that employ free-air carbon dioxide enrichment [21].

We chose to focus on response variables that are directly related to trophic interactions, such as feeding rate, weight gain, and population biomass at a specific trophic level. Some studies reported data from multiple response variables, and we excluded those that were redundant. For example, if a study reported both final herbivore weight and feeding rate from one experimental setup, then we only included feeding rate in our analyses because it is a more direct measure of trophic interactions. When studies reported response variables at multiple time points, we used the data from the final time point.

Studies were included in our analyses if they contained mean and variance data across all four treatment types: control, manipulation of variable A alone, manipulation of variable $B$ alone, and manipulation of variables $A$ and $B$ together. Also, studies had to simultaneously expose species in the different trophic levels to both experimental climate manipulations (e.g., temperature and precipitation). Some of the studies we encountered exposed plants to one climate manipulation and then fed parts of those plants to herbivores exposed to a different climate manipulation. Such studies were excluded from our analyses. Lastly, a small number of studies manipulated three climate change variables within one experimental design. For these studies, we included the response variables from each unique climate variable pairing. Data were mined from graphs presented in each published study using the program Plot Digitizer (version 2.6.3; http://plotdigitizer. sourceforge.net) and, in some cases, data were provided by the authors of the studies. 


\section{Effect size calculations}

We calculated main and interaction effect sizes for each study using methods for factorial meta-analysis $[19,69,70]$. We chose the log response ratio over other metrics, such as Hedge's $d$ [71], because of 1 ) its ability to detect true effects [72], 2) its ability to remain more normally distributed even with small sample sizes [69], 3) its linear nature [69], and 4) its more explicit ties to ecological dynamics [73].

Following [19], main and interaction effect sizes based on a multiplicative model were calculated as

$$
\begin{aligned}
& L_{\mathrm{a}}=\ln \left(\frac{\bar{y}_{\mathrm{a}}}{\bar{y}_{\text {con }}}\right) \\
& L_{\mathrm{b}}=\ln \left(\frac{\bar{y}_{\mathrm{b}}}{\bar{y}_{\text {con }}}\right) \\
& L_{\mathrm{ab}}=\ln \left(\frac{\bar{y}_{\mathrm{ab}}}{\bar{y}_{\mathrm{b}}}\right)-\ln \left(\frac{\bar{y}_{\mathrm{a}}}{\bar{y}_{\text {con }}}\right)
\end{aligned}
$$

where $L_{x}$ is the log response ratio for the indicated response variable (in subscript) and $\bar{y}_{x}$ is the mean value for the indicated response variable (in subscript). Individual estimates of variance were calculated as

$$
\begin{aligned}
& v_{\mathrm{a}}=s_{\mathrm{a}, \text { pooled }}\left(\frac{1}{n_{\text {con }}\left(\bar{y}_{\text {con }}\right)^{2}}+\frac{1}{n_{\mathrm{a}}\left(\bar{y}_{\mathrm{a}}\right)^{2}}\right) \\
& v_{\mathrm{b}}=s_{\mathrm{b}, \text { pooled }}\left(\frac{1}{n_{\text {con }\left(\bar{y}_{\text {con }}\right)^{2}}}+\frac{1}{n_{\mathrm{b}}\left(\bar{y}_{\mathrm{b}}\right)^{2}}\right) \\
& v_{\mathrm{ab}}=s_{\text {ab,pooled }}\left(\frac{1}{n_{\text {con }}\left(\bar{y}_{\text {con }}\right)^{2}}+\frac{1}{n_{\mathrm{a}}\left(\bar{y}_{\mathrm{a}}\right)^{2}}+\frac{1}{n_{\mathrm{b}}\left(\bar{y}_{\mathrm{b}}\right)^{2}}+\frac{1}{n_{\mathrm{ab}}\left(\bar{y}_{\mathrm{ab}}\right)^{2}}\right)
\end{aligned}
$$

where $s_{x, \text { pooled }}$ is the pooled standard deviation for the indicated response variable (in subscript) and $n_{x}$ is the sample size for the indicated response variable (in subscript). The pooled standard deviation was calculated as

$$
\begin{aligned}
& s_{\mathrm{a}, \text { pooled }}=\sqrt{\frac{\left(n_{\mathrm{con}}-1\right)\left(s_{\text {con }}\right)^{2}+\left(n_{\mathrm{a}}-1\right)\left(s_{\mathrm{a}}\right)^{2}}{n_{\mathrm{con}}+n_{\mathrm{a}}-2}} \\
& s_{\mathrm{b}, \text { pooled }}=\sqrt{\frac{\left(n_{\mathrm{con}}-1\right)\left(s_{\mathrm{con}}\right)^{2}+\left(n_{\mathrm{b}}-1\right)\left(s_{\mathrm{b}}\right)^{2}}{n_{\mathrm{con}}+n_{\mathrm{b}}-2}} \\
& s_{\mathrm{ab}, \text { pooled }}=\sqrt{\begin{array}{l}
\left(n_{\mathrm{con}}-1\right)\left(s_{\mathrm{con}}\right)^{2}+\left(n_{\mathrm{a}}-1\right)\left(s_{\mathrm{a}}\right)^{2} \\
\frac{+\left(n_{\mathrm{b}}-1\right)\left(s_{\mathrm{b}}\right)^{2}+\left(n_{\mathrm{ab}}-1\right)\left(s_{\mathrm{ab}}\right)^{2}}{n_{\mathrm{con}}+n_{\mathrm{a}}+n_{\mathrm{b}}+n_{\mathrm{ab}}-4}
\end{array}}
\end{aligned}
$$

where $s_{x}$ is the standard deviation of the mean for the indicated response variable (in subscript). We then calculated 95\% confidence intervals (CI) around each $L_{x}$ value using the equation

$$
L_{x} \pm 1.96 * \sqrt{v_{x}}
$$

where $v_{x}$ is the variance estimate for variable A, variable $B$, or variables $A$ and $B$ together. Following [11], weighted summary effect sizes $(E)$ were calculated for $k$ response variables as

$$
E=\frac{\sum_{i=1}^{i=k}\left(\frac{1}{v_{i}}\right) * e_{i}}{\sum_{i=1}^{i=k}\left(\frac{1}{v_{i}}\right)}
$$

where $v_{i}$ is the variance estimate and $e_{i}$ is the $\log$ response ratio for each response variable. Significant weighted summary effect sizes were those that had 95\% CIs that did not contain zero, and $E$ values were calculated for each climate change variable tested in isolation as well as all variables pooled together.

We based our analyses of multiple interacting climate change variables on an underlying multiplicative model, as opposed to a more conservative additive model [74], because multiplicative models are more ecologically realistic representations of interacting effects [75] and the $\log$ response ratio itself is based on a multiplicative model [76]. Interaction effects were classified as multiplicative (the null hypothesis) if the 95\% CI around the interaction effect size $\left(L_{\mathrm{ab}}\right)$ contained zero. If both variable A and B effect sizes $\left(L_{\mathrm{a}}\right.$ and $\left.L_{\mathrm{b}}\right)$ were positive, the interaction effect was classified as synergistic when the $L_{\mathrm{ab}} 95 \% \mathrm{CI}$ was greater than zero and antagonistic when less than zero. If both $L_{\mathrm{a}}$ and $L_{\mathrm{b}}$ were negative or one was negative and one positive, then the classifications were reversed [19]. Following [74], multiplicative interactions in the multiplicative model are defined as instances where the effect size of the interaction between variables $\mathrm{A}$ and $\mathrm{B}$ is equal to the product of the effect sizes of variables A and B alone. Synergistic interactions are those in which the effect size of the interaction between variables $A$ and $B$ is greater than the product of the effect sizes of variables A and B alone, and antagonistic interactions are those in which the effect size of the interaction between variables $A$ and $B$ is less than the product of the effect sizes of variables $A$ and $B$ alone.

\section{Context dependence}

Cumulatively, the studies included in our meta-analysis explicitly or implicitly tested six different kinds of context dependence: nutrient level, sex, species identity, community composition, genotype, and combinations of climate change variables. We examined each of the six independently to determine if interaction type or interaction effect size magnitude $\left(L_{\mathrm{ab}} \pm 95 \% \mathrm{CI}\right)$ were context dependent. For example, interaction type might be different for males and females (e.g., antagonistic for one and synergistic for the other) because of behavioral or physiological differences 
between the sexes, and interaction effect size magnitude would be significantly different between sexes for a particular study if the $L_{\mathrm{ab}} \pm 95 \% \mathrm{CI}$ ranges for males and females did not overlap.

\section{Publication bias}

The strength of any given meta-analysis can be affected by publication bias, defined as the preferential publication of studies reporting certain kinds of results over those reporting other types of results [77]. This can lead to overestimation of the quantity of significant results reported from a given field of study. To investigate the likelihood of publication bias affecting the results of our own metaanalysis we employed two techniques: Kendall's tau and the fail-safe number. We used Kendall's tau to assess the correlation between effect sizes and variance from each study, with a significant correlation suggesting a high probability of publication bias [78]. We used Rosenthal's fail-safe number to estimate the number of hypothetical additional studies reporting non-significant results needed to reduce the effect size to non-significance [79]. If the fail-safe number exceeds $5 n+10$ ( $n=$ the number of studies used in the meta-analysis), then, we can assume that publication bias likely did not affect our results [79]. We used MetaWin 2.0 (www.metawinsoft.com) to carry out these analyses.

\section{Competing interests}

The authors declare that they have no competing interests.

\section{Authors' contributions}

AER conceived of the study, developed the literature database, performed the meta-analysis, and drafted the manuscript. OJS assisted with the design and execution of the meta-analysis and helped to draft the manuscript. Both authors read and approved the final manuscript.

\section{Acknowledgements}

We thank Rachel Decker, Jennifer Miller, and Robert Buchkowski for commenting on an early draft. AER was generously supported by the Yale Climate and Energy Institute during the preparation of this manuscript. Additional support was provided by the National Science Foundation through Grant No. DEB-1354762.

\section{Author details}

${ }^{1}$ Yale University, Yale Climate and Energy Institute, New Haven, CT, USA. ${ }^{2}$ Yale University, School of Forestry and Environmental Studies, New Haven, $C T$, USA.

Received: 8 May 2014 Accepted: 25 June 2014

Published online: 01 December 2014

\section{References}

1. Schmitz O, Post E, Burns CE, Johnston KM: Ecosystem responses to global climate change: moving beyond color mapping. Bioscience 2003, 53:1199-1205

2. Tylianakis J, Didham RK, Bascompte J, Wardle DA: Global change and species interactions in terrestrial ecosystems. Ecol Lett 2008, 11:1351-1363.

3. Gilman S, Urban MC, Tewksbury J, Gilchrist GW, Holt RD: A framework for community interactions under climate change. Trends Ecol Evol 2010, 25:325-331
4. Traill L, Lim MLM, Sodhi NS, Bradshaw CJA: Mechanisms driving change: altered species interactions and ecosystem function through global warming. J Anim Ecol 2010, 79:937-947.

5. van der Putten W, Macel M, Visser ME: Predicting species distribution and abundance responses to climate change: why it is essential to include biotic interactions across trophic levels. Philos Trans Roy Soc B 2010, 365:2025-2034.

6. Post E: Ecology of Climate Change: the Importance of Biotic Interactions. Princeton: Princeton University Press; 2013.

7. Jamieson M, Trowbridge AM, Raffa KF, Lindroth RL: Consequences of climate warming and altered precipitation patterns for plant-insect and multitrophic interactions. Plant Physiol 2012, 160:1719-1727.

8. Harrington R, Woiwod I, Sparks T: Climate change and trophic interactions. Trends Ecol Evol 1999, 14:146-150.

9. Crain C, Kroeker K, Halpern BS: Interactive and cumulative effects of multiple human stressors in marine systems. Ecol Lett 2008, 11:1304-1315.

10. Todgham AE, Stillman JH: Physiological response to shifts in multiple environmental stressors: relevance in a changing world. Integr Comp Biol 2013, 53:539-544.

11. Hillebrand H: Meta-analysis in ecology. In Encyclopedia of Life Sciences. Chichester: John Wiley \& Sons; 2008. doi:10.1002/9780470015902. a9780470003272.

12. Gurevitch J, Hedges LV: Statistical issues in ecological meta-analyses. Ecology 1999, 80:1142-1149.

13. Arnqvist G, Wooster D: Meta-analysis: synthesizing research findings in ecology and evolution. Trends Ecol Evol 1995, 10:236-240.

14. Breitburg D, Baxter JW, Hatfield CA, Howarth RW, Jones CG, Lovett GM Wigand C: Understanding effects of multiple stressors: ideas and challenges. In Successes, Limitations, and Frontiers in Ecosystem Science. Edited by Pace M, Groffman PM. New York: Springer-Verlag; 1998:416-431.

15. Sala O, Chapin FS III, Armesto JJ, Berlow E, Bloomfield J, Dirzo R, HuberSanwald E, Huenneke LF, Jackson RB, Kinzig A, Leemans R, Lodge DM, Mooney HA, Oesterheld M, Poff NL, Sykes MT, Walker BH, Walker M, Wall $\mathrm{DH}$ : Global biodiversity scenarios for the year 2100 . Science 2000, 287:1770-1774.

16. Norby R, Luo $Y$ : Evaluating ecosystem responses to rising atmospheric $\mathrm{CO}_{2}$ and global warming in a multi-factor world. New Phytol 2004, 162:281-293.

17. Darling E, Cote IM: Quantifying the evidence for ecological synergies. Ecol Lett 2008, 11:1278-1286.

18. Dieleman W, Vicca S, Dijkstra FA, Hagedorn F, Hovenden MJ, Larsen KS, Morgan JA, Volder A, Beier C, Dukes JS, King J, Leuzinger S, Linder S, Luo Y, Oren $R$, de Angelis $P$, Tingey D, Hoosbeek MR, Janssens IA: Simple additive effects are rare: a quantitative review of plant biomass and soil process responses to combined manipulations of $\mathrm{CO}_{2}$ and temperature. Global Change Biol 2012, 18:2681-2693.

19. Harvey B, Gwynn-Jones D, Moore PJ: Meta-analysis reveals complex marine biological responses to the interactive effects of ocean acidification and warming. Ecol Evol 2013, 3:1016-1030.

20. Altieri A, Bertness MD, Coverdale TC, Herrmann NC, Angelini C: A trophic cascade triggers collapse of a salt-marsh ecosystem with intensive recreational fishing. Ecology 2012, 93:1402-1410.

21. Ainsworth $E$, Long SP: What have we learned from 15 years of free-air $\mathrm{CO}_{2}$ enrichment (FACE)? A meta-analytic review of the responses of photosynthesis, canopy properties and plant production to rising $\mathrm{CO}_{2}$. New Phytol 2005, 165:351-372.

22. Zvereva $\mathrm{E}$, Kozlov MV: Consequences of simultaneous elevation of carbon dioxide and temperature for plant-herbivore interactions: a metaanalysis. Global Change Biol 2006, 12:27-41.

23. DeLucia E, Nabity PD, Zavala JA, Berenbaum MR: Climate change: resetting plant-insect interactions. Plant Physiol 2012, 160:1677-1685.

24. Christensen M, Graham MD, Vinebrooke RD, Findlay DL, Paterson MJ, Turner MA: Multiple anthropogenic stressors cause ecological surprises in boreal lakes. Global Change Biol 2006, 12:2316-2322.

25. Bouvy M, Bettarel $Y$, Bouvier C, Domaizon I, Jacquet S, Le Floc'h E, Montanié H, Mostajir B, Sime-Ngando T, Torréton JP, Vidussi F, Bouvier T: Trophic interactions between viruses, bacteria and nanoflagellates under various nutrient conditions and simulated climate change. Environ Microbio/ 2011, 13:1842-1857

26. Lewandowska A, Sommer U: Climate change and the spring bloom: a mesocosm study on the influence of light and temperature on 
phytoplankton and mesozooplankton. Mar Ecol Prog Ser 2010, 405:101-111.

27. Eklof J, Alsterberg C, Havenhand JN, Sundback K, Wood HL, Gamfeldt L: Experimental climate change weakens the insurance effect of biodiversity. Ecol Lett 2012, 15:864-872.

28. Alsterberg C, Eklof JS, Gamfeldt L, Havenhand JN, Sundback K: Consumers mediate the effects of experimental ocean acidification and warming on primary producers. Proc Natl Acad Sci 2013, 110:8603-8608.

29. Burnell O, Russell BD, Irving AD, Connell SD: Eutrophication offsets increased sea urchin grazing on seagrass caused by ocean warming and acidification. Mar Ecol Prog Ser 2013, 485:37-46.

30. Poore A, Graba-Landry A, Favret M, Brennand HS, Byrne M, Dworjanyn SA: Direct and indirect effects of ocean acidification and warming on a marine plant-herbivore interaction. Oecologia 2013, 173:1113-1124.

31. Blake R, Duffy JE: Grazer diversity affects resistance to multiple stressors in an experimental seagrass ecosystem. Oikos 2010, 119:1625-1635.

32. Dyer $L$, Richards LA, Short SA, Dodson CD: Effects of $\mathrm{CO}_{2}$ and temperature on tritrophic interactions. PLoS One 2013, 8:e62528.

33. Hoover J, Newman JA: Tritrophic interactions in the context of climate change: a model of grasses, cereal aphids and their parasitoids. Global Change Biol 2004, 10:1197-1208.

34. Johns $C_{1}$ Hughes $\mathrm{L}$ : Interactive effects of elevated $\mathrm{CO}_{2}$ and temperature on the leaf-miner Dialectica scalariella Zeller (Lepidoptera: Gracillariidae) in Paterson's curse, Echium plantagineum (Boraginaceae). Global Change Biol 2002, 8:142-152

35. Johns $C$, Beaumont $L$, Hughes $L$ : Effects of elevated $\mathrm{CO}_{2}$ and temperature on development and consumption rates of Octotoma championi and $O$. scabripennis feeding on Lantana camara. Entomol Exp Appl 2003, 108:169-178.

36. Williams R, Lincoln DE, Norby RJ: Development of gypsy moth larvae feeding on red maple saplings at elevated $\mathrm{CO}_{2}$ and temperature. Oecologia 2003, 137:114-122

37. Flynn D, Sudderth EA, Bazzaz FA: Effects of aphid herbivory on biomass and leaf-level physiology of Solanum dulcamara under elevated temperature and $\mathrm{CO}_{2}$. Environ Exp Bot 2006, 56:10-18.

38. Murray T, Ellsworth DS, Tissue DT, Riegler M: Interactive direct and plantmediated effects of elevated atmospheric $\left[\mathrm{CO}_{2}\right]$ and temperature on a eucalypt-feeding insect herbivore. Global Change Biol 2013, 19:1407-1416.

39. Murray T, Tissue DT, Ellsworth DS, Riegler M: Interactive effects of pre-industrial, current and future $\left[\mathrm{CO}_{2}\right]$ and temperature on an insect herbivore of Eucalyptus. Oecologia 2013, 171:1025-1035.

40. Williams $\mathrm{R}$, Norby RJ, Lincoln DE: Effects of elevated $\mathrm{CO}_{2}$ and temperature-grown red and sugar maple on gypsy moth performance. Global Change Biol 2000, 6:685-695.

41. Stevnbak K, Scherber C, Gladbach DJ, Beier C, Mikkelsen TN, Christensen S: Interactions between above- and belowground organisms modified in climate change experiments. Nat Clim Change 2012, 2:805-808.

42. Andresen L, Konestabo HS, Maraldo K, Holmstrup M, Ambus P, Beier C, Michelsen A: Organic matter flow in the food web at a temperate heath under multifactorial climate change. Rapid Commun Mass Spectrom 2011 25:1485-1496.

43. Scherber C, Gladbach DJ, Stevnbak K, Karsten RJ, Schmidt IK, Michelsen A, Albert KR, Larsen KS, Mikkelsen TN, Beier C, Christensen S: Multi-factor climate change effects on insect herbivore performance. Ecol Evol 2013, 3:1449-1460.

44. Eisenhauer N, Cesarz S, Koller R, Worm K, Reich PB: Global change belowground: impacts of elevated $\mathrm{CO}_{2}$, nitrogen, and summer drought on soil food webs and biodiversity. Global Change Biol 2012, 18:435-447.

45. Roth $\mathrm{S}, \mathrm{McD}$ onald EP, Lindroth RL: Atmospheric $\mathrm{CO}_{2}$ and soil water availability: consequences for tree-insect interactions. Can J Forest Res 1997, 27:1281-1290

46. Zhang J, Xing G, Liao J, Hou Z, Wang G, Wang Y: Effects of different atmospheric $\mathrm{CO}_{2}$ concentrations and soil moistures on the populations of bird cherry-oat aphid (Rhopalosiphum padi) feeding on spring wheat. Eur J Entomol 2003, 100:521-530.

47. Holton M, Lindroth RL, Nordheim EV: Foliar quality influences treeherbivore-parasitoid interactions: effects of elevated $\mathrm{CO}_{2}, \mathrm{O}_{3}$, and plant genotype. Oecologia 2003, 137:233-244.

48. Awmack C, Harrington R, Lindroth RL: Aphid individual performance may not predict population responses to elevated $\mathrm{CO}_{2}$ or $\mathrm{O}_{3}$. Global Change Biol 2004, 10:1414-1423.
49. Dermody O, O'Neill BF, Zangerl AR, Berenbaum MR, DeLucia EH: Effects of elevated $\mathrm{CO}_{2}$ and $\mathrm{O}_{3}$ on leaf damage and insect abundance in a soybean agroecosystem. Arthropod-Plant Interact 2008, 2:125-135.

50. Kopper B, Lindroth RL: Effects of elevated carbon dioxide and ozone on the phytochemistry of aspen and performance of an herbivore. Oecologia 2003, 134:95-103.

51. Kopper B, Lindroth RL: Responses of trembling aspen (Populus tremuloides) phytochemistry and aspen blotch leafminer (Phyllonorycter tremuloidiella) performance to elevated levels of atmospheric $\mathrm{CO}_{2}$ and $\mathrm{O}_{3}$. Agric For Entomol 2003, 5:17-26.

52. Kopper $\mathrm{B}$, Lindroth RL, Nordheim EV: $\mathrm{CO}_{2}$ and $\mathrm{O}_{3}$ effects on paper birch (Betulaceae: Betula papyrifera) phytochemistry and whitemarked tussock moth (Lymantriidae: Orgyia leucostigma) performance. Environ Entomol 2001, 30:1119-1126.

53. Mondor E, Tremblay MN, Awmack CS, Lindroth RL: Altered genotypic and phenotypic frequencies of aphid populations under enriched $\mathrm{CO}_{2}$ and $\mathrm{O}_{3}$ atmospheres. Global Change Biol 2005, 11:1990-1996.

54. Mondor E, Awmack CS, Lindroth RL: Individual growth rates do not predict aphid population densities under altered atmospheric conditions. Agric For Entomol 2010, 12:293-299.

55. Percy K, Awmack CS, Lindroth RL, Kubiske ME, Kopper BJ, Isebrands JG, Pregitzer KS, Hendrey GR, Dickson RE, Zak DR, Oksanen E, Sober J, Harrington R, Karnosky DF: Altered performance of forest pests under atmospheres enriched by $\mathrm{CO}_{2}$ and $\mathrm{O}_{3}$. Nature 2002, 420:403-407.

56. Vigue $\mathrm{L}$, Lindroth RL: Effects of genotype, elevated $\mathrm{CO}_{2}$ and elevated $\mathrm{O}_{3}$ on aspen phytochemistry and aspen leaf beetle Chrysomela crotchi performance. Agric For Entomol 2010, 12:267-276.

57. Perdikis D, Lykouressis DP, Economou LP: The influence of temperature, photoperiod and plant type on the predation rate of Macrolophus pygmaeus on Myzus persicae. Bio Control 1999, 44:281-289.

58. Leuzinger S, Luo Y, Beier C, Dieleman W, Vicca S, Korner C: Do global change experiments overestimate impacts on terrestrial ecosystems? Trends Ecol Evol 2011, 26:236-241.

59. Mattson W: Herbivory in relation to plant nitrogen content. Annu Rev Ecol Syst 1980, 11:119-161.

60. Fajer $\mathrm{E}$ : The effects of enriched $\mathrm{CO}_{2}$ atmospheres on plant-insect herbivore interactions: growth responses of larvae of the specialist butterfly, Junonia coenia (Lepidoptera: Nymphalidae). Oecologia 1989, 81:514-520.

61. Lincoln D, Fajer ED, Johnson RH: Plant-insect herbivore interactions in elevated $\mathrm{CO}_{2}$ environments. Trends Ecol Evol 1993, 8:64-68.

62. Bale J, Masters GJ, Hodkinson ID, Awmack C, Bezemer TM, Brown VK, Butterfield J, Buse A, Coulson JC, Farrar J, Good JEG, Harrington R, Hartley S, Jones $T H$, Lindroth RL, Press MC, Symrnioudis I, Watt AD, Whittaker JB: Herbivory in global climate change research: direct effects of rising temperature on insect herbivores. Global Change Biol 2002, 8:1-16.

63. Nicolas G, Sillans D: Immediate and latent effects of carbon dioxide on insects. Annu Rev Entomol 1989, 34:97-116.

64. Neven L: Physiological responses of insects to heat. Postharvest Biol Technol 2000, 21:103-111.

65. Lindroth $\mathrm{R}$ : Impacts of elevated atmospheric $\mathrm{CO}_{2}$ and $\mathrm{O}_{3}$ on forests: phytochemistry, trophic interactions, and ecosystem dynamics. J Chem Ecol 2010, 36:2-21.

66. Robinson $E$, Ryan GD, Newman JA: A meta-analytical review of the effects of elevated $\mathrm{CO}_{2}$ on plant-arthropod interactions highlights the importance of interacting environmental and biological variables. New Phytologist 2012, 194:321-336.

67. Janssens L, Van KD, Debecker S, Bervoets L, Stoks R: Local adaptation and the potential effects of contaminant on predator avoidance and antipredator responses under global warming: a space-for-time substitution approach. Evol App/ 2014, doi:10.1111/eva.12141.

68. Suttle K, Thomsen MA, Power ME: Species interactions reverse grassland responses to changing climate. Science 2007, 315:640-642.

69. Hedges L, Gurevitch J, Curtis PS: The meta-analysis of response ratios in experimental ecology. Ecology 1999, 80:1150-1156.

70. Hawkes C, Sullivan JJ: The impact of herbivory on plants in different resource conditions: a meta-analysis. Ecology 2001, 82:2045-2058.

71. Gurevitch J, Morrison JA, Hedges LV: The interaction between competition and predation: a meta-analysis of field experiments. Am Nat 2000, 155:435-453.

72. Lajeunesse M, Forbes MR: Variable reporting and quantitative reviews: a comparison of three meta-analytical techniques. Ecol Lett 2003, 6:448-454. 
73. Osenberg C, Sarnelle O, Cooper SD: Effect size in ecological experiments: the application of biological models in meta-analysis. Am Nat 1997, 150:798-812.

74. Folt C, Chen CY, Moore MV, Burnaford J: Synergism and antagonism among multiple stressors. Limnol Oceanogr 1999, 44:864-877.

75. Sih $A$, Englund G, Wooster D: Emergent impacts of multiple predators on prey. Trends Ecol Evol 1998, 13:350-355.

76. Morris W, Hufbauer RA, Agrawal AA, Bever JD, Borowicz VA, Gilbert GS,

Maron JL, Mitchell CE, Parker IM, Power AG, Torchin ME, Vazquez DP: Direct and interactive effects of enemies and mutualists on plant performance: a meta-analysis. Ecology 2007, 88:1021-1029.

77. Begg C: Publication bias. In The Handbook of Research Synthesis. Edited by Cooper H, Hedges LV. New York: Russell Sage Foundation; 1994:399-409.

78. Begg C, Mazumdar M: Operating characteristics of a rank correlation test for publication bias. Biometrics 1994, 50:1088-1101.

79. Rosenthal R: The "file drawer problem" and tolerance for null results. Psychol Bull 1979, 86:638-641.

doi:10.1186/s40665-014-0008-y

Cite this article as: Rosenblatt and Schmitz: Interactive effects of multiple climate change variables on trophic interactions: a

meta-analysis. Climate Change Responses 2014 1:8.

\section{Submit your next manuscript to BioMed Central and take full advantage of:}

- Convenient online submission

- Thorough peer review

- No space constraints or color figure charges

- Immediate publication on acceptance

- Inclusion in PubMed, CAS, Scopus and Google Scholar

- Research which is freely available for redistribution 